\title{
Trust is crucial in lockdown-and beyond
}

\author{
Fiona Godlee editor in chief
}

The BMJ

Lockdown is preventing infections and reducing deaths from covid-19. But it brings its own profound consequences for health and wellbeing, as Margaret Douglas and colleagues report this week (doi:10.1136/bmj.m1557). Loss of income and education, unemployment, uncertainty, social isolation, and domestic violence are just some of the emerging negative outcomes of the mass closure of businesses and schools, with disproportionate effect on people with fewer resources and poorer health, they say. The long term harms, including increased social and health inequality, may well dwarf the death toll of covid-19 itself.

Even in the short term, data indicate an excess of deaths not directly explained by covid-19, possibly because of investigations and treatments being postponed and patients not seeking necessary care. John Appleby says the data are incomplete, too uncertain, and too fast moving to support reliable conclusions (doi:10.1136/bmj.m1607), a concern echoed by Sheila Bird, who says the UK's reporting of swab tests is "a travesty of science" (doi:10.1136/bmj.m1664).

There is also the rapidly unfolding scandal of deaths in care homes. Historically neglected and marginalised, they now have the added pressure of caring for patients who have been discharged from hospital so as to make space for covid-19 but with no additional resources, says David Oliver (doi:10.1136/ bmj.m1629). "The current crisis has brought into sharp focus issues around funding, staffing, and support for care homes that we should have tackled many years ago," he says. It's time now to push for a national health and social care service (doi:10. 1136/bmj.m1465).

All this sets the stage for some finely balanced decisions about when and how to lift the lockdown. Much hope is invested in a vaccine, with 82 potential candidates and seven approved for human trials around the world (doi:10.1136/bmj.m1679). But even the most optimistic timeframe is $12-18$ months, and the World Health Organization has repeatedly warned countries not to rely on a vaccine to end the pandemic.

Instead its guidance has emphasised the need for mass testing, contact tracing, and isolation (doi:10.1136/bmj.m1556). Sufficient capacity for this crucial element of communicable disease control is one of the three criteria set out in the joint European road map towards lifting restrictions (doi:10.1136/ bmj.m1549), yet it doesn't feature among the UK government's five tests. It is only hinted at under the fourth heading of ensuring an adequate supply of tests and PPE. After its much criticised and as yet unjustified decision on 12 March to stop testing in the community (doi:10.1136/bmj.m1284), the government has some major catching up to do. Speaking to The $B M J$, Allyson Pollock cited fragmentation and decimation of the local communicable disease response as a key reason for the failure to initiate contact tracing on the ground (doi:10.1136/ bmj.m1638). She called for rapid rebuilding of local capacity and integration with GPs and environmental health professionals.

The decision to stop testing and the half hearted restarting (doi:10.1136/bmj.m1591) will be one of many things needing scrutiny in the aftermath of this pandemic. So too will the failure to procure sufficient personal protective equipment despite repeated warnings of the need, and the apparent downgrading of guidance to eke out inadequate supply (doi:10.1136/bmj. m1665). The workings and makeup of the government's Scientific Advisory Group for Emergencies (SAGE) are at last beginning to emerge from the shadows (doi:10.1136/bmj. m1707), but where are the minutes? And now that we know the group's composition, where are the experts in social care and communicable disease control? Why so few women, why no one from an ethnic minority background, and why the political advisers? When decisions of this magnitude are made and public trust is at stake, it matters more than ever who is in the room. 